\title{
A Guide to the Influence of Ground Reaction on Ship
} Stability

\author{
Ahmed Helmy Abouelfadl and Essam Eldin Youssef Abdelraouf \\ College of Maritime Transport \& Technology, Arab Academy for Science, Technology and Maritime Transport (AAST\&MT), \\ Alexandria 1029, Egypt
}

\begin{abstract}
Grounded ship faces up exceptionally different stability forces unlike in her normal operating condition. This critical situation must be corrected as soon as can minimize hull stress, the risk of pollution and stability failure. Re-floating the ship need full understanding of the impact of ground reaction (R) on the ship buoyancy and stability. Re-floating the ship has different phases and there are several immediate actions that should be taken by ship's crew; one of these phases is re-calculation of ship stability conditions. In this paper, a guide to understanding the effect of the ground reaction $(\mathrm{R})$, determines the amount of ground pressure and its location. With consideration of the seabed form whether symmetric of asymmetric. Calculating the magnitude of the ground reaction $(\mathrm{R})$ using different applicable methods, explaining the effect of using weight to re-float the ship by her own means, focusing on GM calculation after grounding.
\end{abstract}

Key words: Ship grounding, ground reaction (R), ground pressure (P), neutral loading point and ship re-floating.

\section{Introduction}

Grounding is one of the most frequent maritime accident [1]. When a ship runs aground whether due to a navigation error or a failure in an engine, it is no longer in her normal operating conditions. Where there are different forces affecting ship's buoyancy and stability. This disorder in ship's conditions and her stability characteristics due to grounding requires attention and re-evaluation for overall ship's stability condition. The ship in grounded position is in a critical situation. Time is an essential factor, the longer the ship stays in grounded position, the higher possibilities are for more damages and casualties. If proper actions are not taken right away by the crew, ship casualties can be deteriorated, affecting more losses to the crew, cargo, environment and the ship itself.

The decision re-floats the ship based on ship condition after grounding, if it is still intact or damaged. In case that the ship is still intact after grounding, there are different methods or a combination to re-float the

Corresponding author: Ahmed Helmy Abouelfadl, M.Sc., research fields: ship stability and operations. ship depends on the way that the ship reclines on the seabed, with consideration to many other aspects related to the ship itself and her structural strength or others external aspects such as weather, sea, seabed, location and time.

Refloating operations have three phases. The stabilization is the first phase taken by the crew to restrain the ship in same grounding position and hold the ship from stepping more a ground and prevent furthermore damage to the ship. The re-floating is the second phase to implement the re-floating plan, considering all effected aspects, changes in stability characteristics after grounding. The post re-floating is the third phase when the ship is again floating freely and safely.

Ship re-floatation requires a good understanding for the influence of ground on the ship, stability characteristics of the ship during grounding and calculation of weights changes to establish an adequate method to re-float the ship.

\section{Ground Reaction (R)}

A grounded ship is no longer floating freely by her 
own buoyancy. Part of her weight is supported by sea water and part by seabed, this disparity in buoyancy force between sea water and seabed is a loss of force of buoyancy. Causing a significant difference is in her normal operating and stability condition. Loss of buoyancy by the part supported by seabed is called ground reaction $(\mathrm{R})$. The ship's weight carried by the ground exactly equivalent to buoyancy lost. This loss of buoyancy called total ground reaction (R), symbolized by $(\mathrm{R})$, and was measured in long tons. Where total ground reaction considered a loss of buoyancy or added weight, the calculation of the total ground reaction $(\mathrm{R})$ amount and the effect location is necessary and important for stability calculation, stresses and re-floating operation. Especially that the total ground reaction $(\mathrm{R})$ is variable due to different factors such as changes in ship's weight or ship's buoyancy.

Ship displacement (W)

$$
\begin{aligned}
& =\text { Ship Buoyancy }(\mathrm{B}) \\
& + \text { Total ground reaction }(\mathrm{R})
\end{aligned}
$$

\section{Determination of Total Ground Reaction (R) Location}

Calculation of total ground reaction $(\mathrm{R})$ or added weight on ship stability and stresses, requires determination the exact location of the total Ground reaction. It can be approximately located based on grounding length (l) and the way the ship touches the ground. The grounded ship centered about the center of ground reaction area and it may spin when side force effects the ship.

If the ship only grounded on one section of its length, the center of the total ground reaction $(\mathrm{R})$ area can be found by calculating the sum of the moments about its LCG (longitudinal center of gravity) (Fig. 1).

$$
\begin{aligned}
\mathrm{Bd}_{2} & =\mathrm{Rd}_{2} \\
\mathrm{~d}_{1} & =\frac{\mathrm{Bd}_{2}}{\mathrm{R}}
\end{aligned}
$$

where,

$$
\begin{aligned}
& B=\text { Actual force of buoyancy. } \\
& R=\text { Total ground reaction (R). } \\
& d_{2}=\text { Distance from LCB to LCG (HBG). }
\end{aligned}
$$

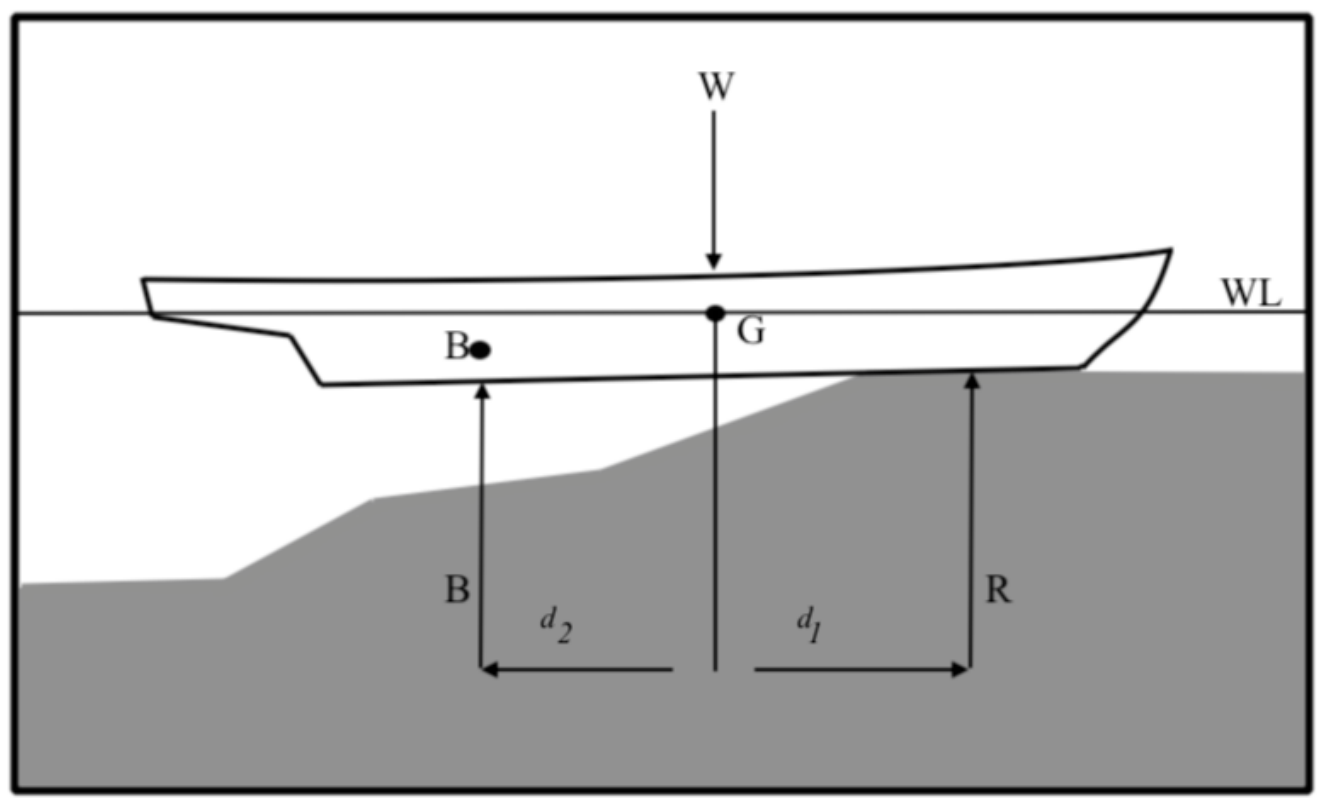

Fig. 1 Determination of total ground reaction (R) location about (LCG). 
$\mathrm{d}_{1}=$ Distance from LCG to the center of total ground reaction $(\mathrm{R})$.

LCB (Longitudinal center of buoyancy) can be found in hydrostatic table or curve with actual draft after grounding; correction needed if the ship trimmed:

$\mathrm{BB}_{1}=\frac{\mathrm{BM}_{\mathrm{L}} \cdot t}{\mathrm{~L}}$

where,

$\mathrm{BB}_{1}=$ Shift of LCB due to trim.

$\mathrm{BM}_{\mathrm{L}}=$ Longitudinal metacentric radius.

$\mathrm{t}=$ Ship's trim.

$\mathrm{L}=$ Ship's length.

LCG could be changed due to grounding, so that the exact location of LCG may be inaccurate, in that case, the center of the total ground reaction $(R)$ area can be found by calculating the sum of the moments about the center of floatation ( $\left.F_{c}\right)$ (Fig. 2).

$$
\begin{aligned}
& \mathrm{Bd}_{2}=\mathrm{Rd}_{1} \\
& \mathrm{~d}_{1}=\frac{\mathrm{Bd}_{2}}{\mathrm{R}}
\end{aligned}
$$

where,

$\mathrm{B}=$ Actual force of buoyancy.

$\mathrm{R}=$ Total ground reaction $(\mathrm{R})$.

$\mathrm{d}_{2}=$ Distance from center of buoyancy LCB to center of floatation (LCF).

$\mathrm{d}_{1}=$ Distance from LCF to the center of total ground reaction $(\mathrm{R})$.

\section{Distribution of Ground Reaction (R)}

The distribution of the pressure on ship's hull due to total ground reaction $(\mathrm{R})$ effect along the grounded length $\left(l_{g}\right)$, except if the ship grounded on summit seabed (single point grounding), in that case, calculation requires more attention. There are many factors else affecting the distribution of total ground reaction such as seabed sloping, seabed composition, seabed topography, hull shape, hull deformation, ship's weight and buoyancy distribution on the ship's hull; and all is difficult to quantize, wherefore it is not easy to determine the distribution of total ground reaction about the location of total ground reaction center.

The symbol $(\mathrm{R})$ is referred to ground reaction per meter length along the grounded length $\left(l_{g}\right)$, there are two assumptions regarding the distribution of the total ground reaction, with consideration to grounding situation and seabed sloping, either to be symmetric or asymmetric.

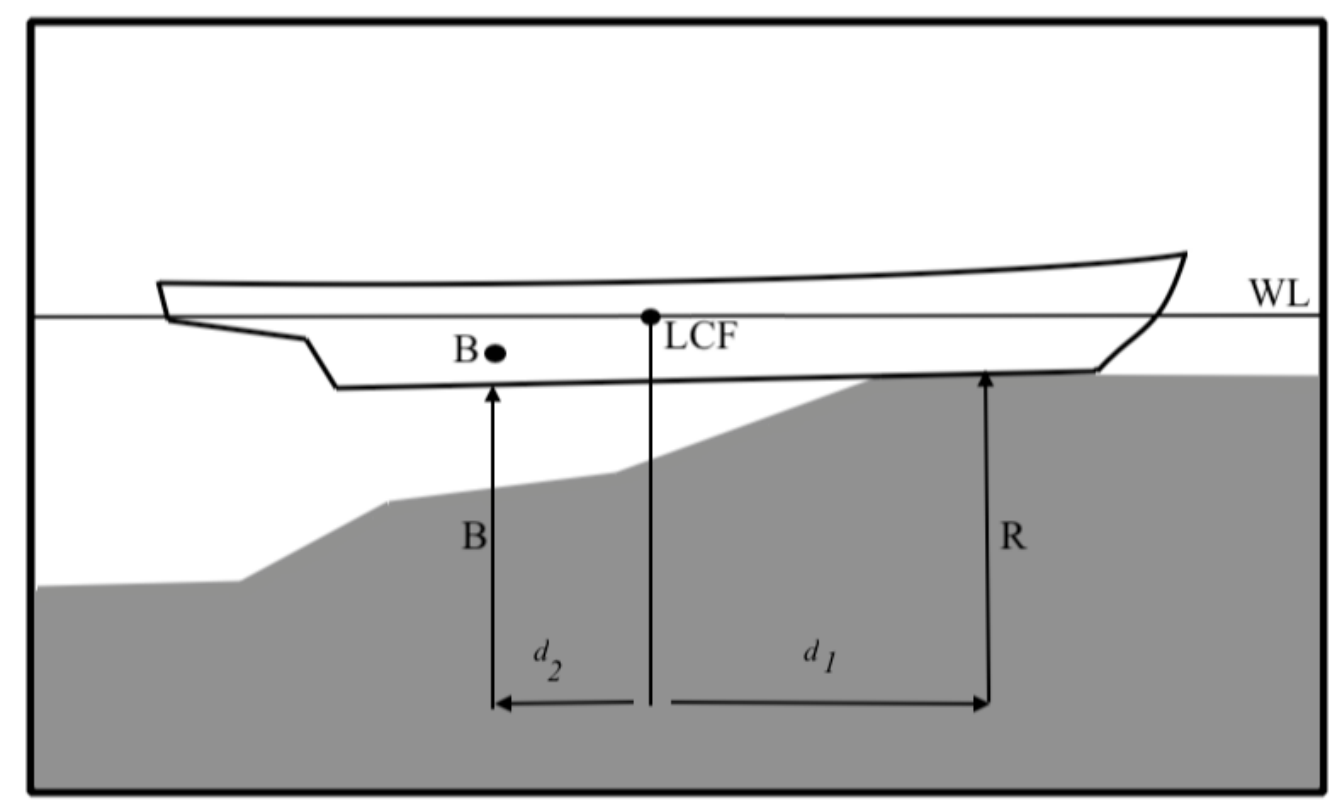

Fig. 2 Determination of total ground reaction (R) location about (LCF). 


\subsection{Symmetric Distribution of Ground Reaction (R)}

If the total ground reaction symmetrical distribution along the ground length (Fig. 3):

Total ground reaction $(\mathrm{R})$

$$
\begin{aligned}
& =\text { ground reaction }(\mathrm{r}) \text { tons } \\
& / m x \text { ground length }\left(l_{g}\right) m=\text { tons }
\end{aligned}
$$

The distribution refers to be at the geometric center of the ground length $\left(l_{g}\right)$.

$$
\mathrm{r}=\frac{\mathrm{R}}{l_{g}}
$$

where,

$$
\begin{aligned}
& \mathrm{r}=\text { Unit ground reaction, tons per } 1 \mathrm{~m}, \\
& \mathrm{R}=\text { Total Ground Reaction }(\mathrm{R}) \text { tons. } \\
& \mathrm{l}_{\mathrm{g}}=\text { Ground length, } \mathrm{m} .
\end{aligned}
$$

\subsection{Asymmetric Distribution of Ground Reaction (R)}

\subsubsection{Uniformly Sloping Seabed}

When the seabed sloping uniformly (Fig. 4), the ship endures ground pressure $\left(\mathrm{P}_{\mathrm{r}}\right)$ all over the ship's length. The ground pressure $\left(\mathrm{P}_{\mathrm{r}}\right)$ increases gradually from zero at the point of the last contact to the maximum at the point of the first contact; where most strong ground pressure $\left(\mathrm{P}_{r}\right)$ is on the end of top slop. In that case, the distribution of the ground pressure $\left(\mathrm{P}_{\mathrm{r}}\right)$ would be same as triangle with height $\left(\mathrm{P}_{\max }\right)$ at the triangle base, in that case, the ground pressure $\left(\mathrm{P}_{\mathrm{r}}\right)$ will be at the geometric center of the triangle area, which is $1 / 3$ of the ground length $\left(l_{g}\right)$ from the triangle base.

$$
P_{\max }=\frac{2 \mathrm{R}}{l_{g} b_{a v g}}
$$

where,

$\mathrm{P}_{\max }=$ Maximum ground pressure, tons per $\mathrm{m}^{2}$.

$\mathrm{R}=$ Total ground reaction $(\mathrm{R})$ tons.

$\mathrm{l}_{\mathrm{g}}=$ Ground length, $\mathrm{m}$.

$\mathrm{b}_{\mathrm{avg}}=$ Average breadth of contact area over ground length, $\mathrm{m}$.

Unit ground reaction $(\mathrm{R})$ at any point is equal to:

$$
\mathrm{r}=\mathrm{P}_{\mathrm{r}} \mathrm{b}
$$

where,

$$
\mathrm{b}=\text { Breadth of contact area, } \mathrm{m}^{2} \text {. }
$$

If the center of the ground length $\left(l_{g}\right)$ and calculated total ground reaction $(\mathrm{R})$ or close to the same location, estimated refer to symmetrical distribution for ground reaction pressure about that point, where the bending moment supposed to be maximum.

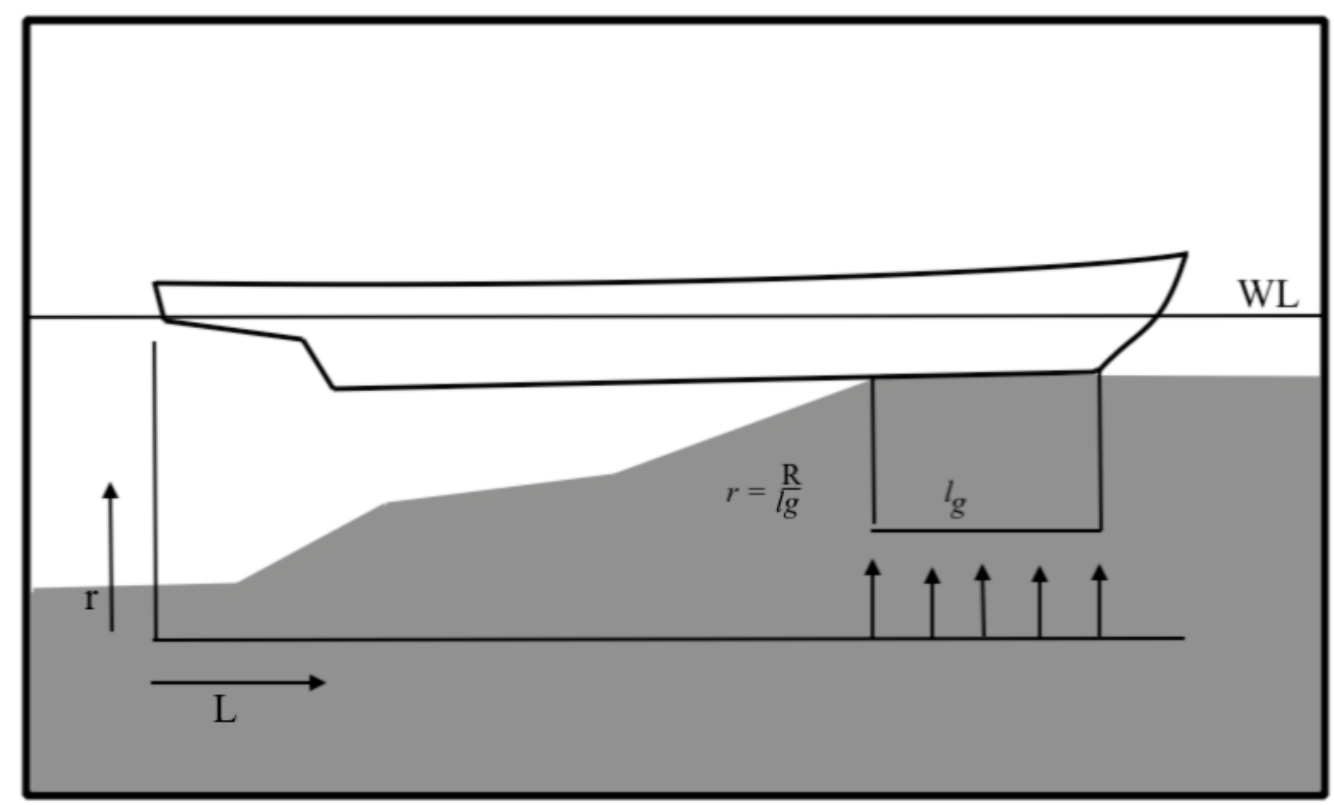

Fig. 3 Symmetric distribution of ground reaction (R). 


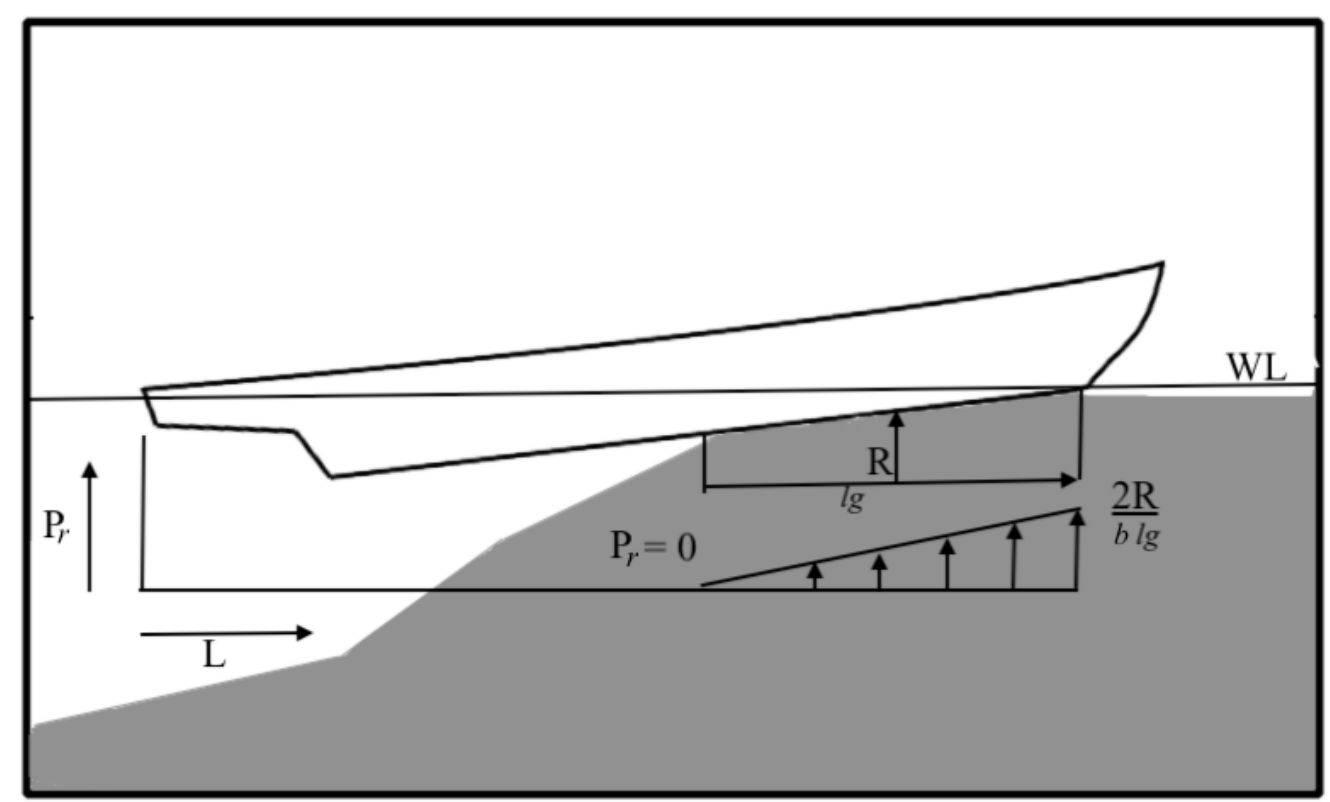

Fig. 4 Asymmetric distribution of ground reaction (R) by uniformly sloping seabed.

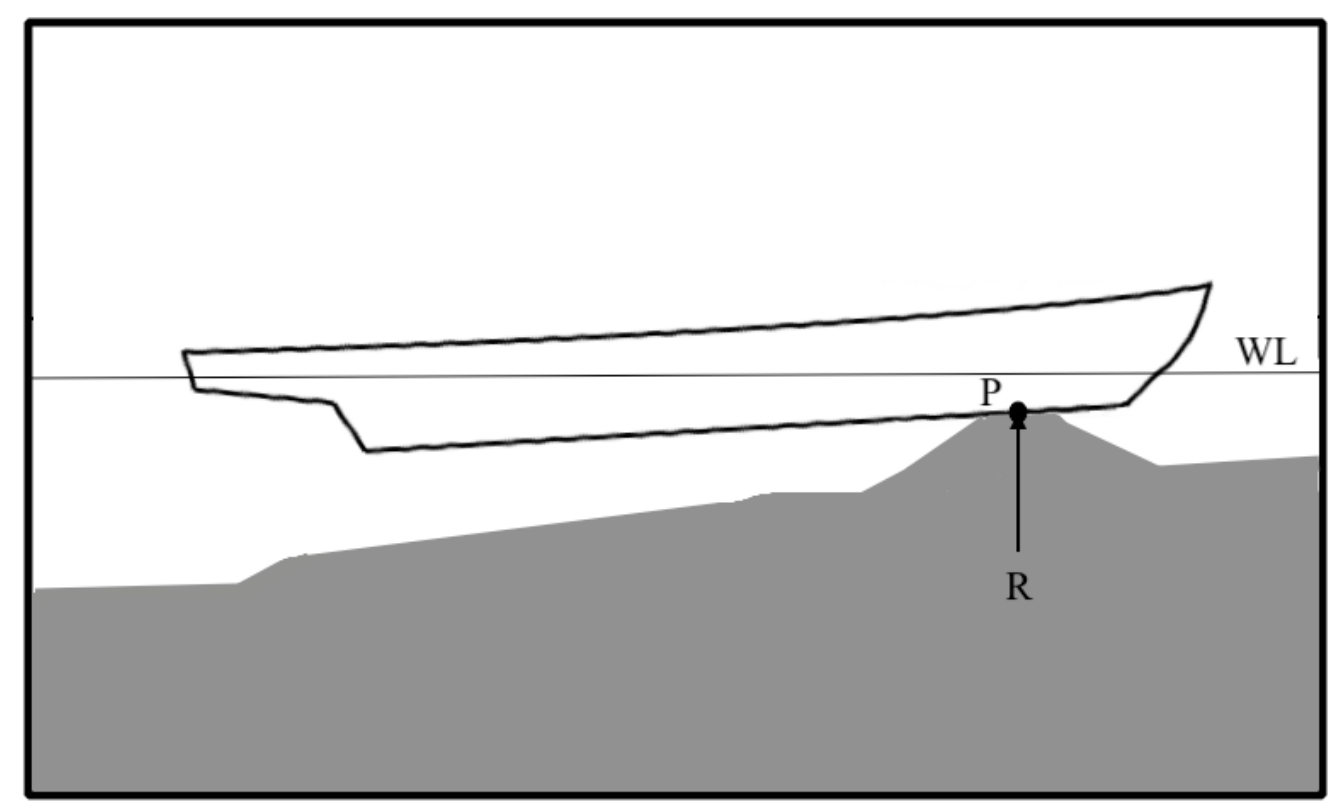

Fig. 5 Asymmetric distribution of ground reaction $(R)$ by a single point of grounding.

If the center of ground reaction (R) located on any side of the ground length $\left(l_{g}\right)$, estimated refer to asymmetrical distribution for ground reaction pressure $\left(\mathrm{P}_{\mathrm{r}}\right)$ about that point, where is distribution centered at that end.

\subsubsection{Single Point of Grounding}

When the ship grounding at summit seabed and supported at a single point, the ship restricted at that point $(\mathrm{P})$, both the total ground pressure $\left(\mathrm{P}_{\mathrm{r}}\right)$ and ground reaction concentrated at that point. The ship cannot sink deeper or rise until the draft at this point is reduced.

\subsubsection{Multiple Points of Grounding}

When the ship is grounded on two separated points, such as two summits, the total ground reaction (R) can be calculated by sum the two moments about one of the grounding points. To sum weight and buoyancy moments, the locations of LCG and LCB must be 
known with fair accuracy.

\section{Calculate the Magnitude of Total Ground Reaction (R)}

Calculating the amount of total ground reaction (R) is necessary and important for stability calculation and the method re-floating the ship; it has considerable influence on the ship's trim, causes an inconvenient bodily rise and changing in all stability characteristics. There are common methods to re-float and bring out the ship significantly with minimum hull damages and without pollution to the marine environment; by her own means either by pumping ballast water in/out, shift ballast between tanks, lightering cargo or even by using main engine and anchors. There are five mathematical methods to calculate the total ground reaction (R). Not all methods are applicable for all grounding cases. Choosing the method based on grounding condition and information is available before and after grounding, such as ship's draft. The total ground reaction (R) acts much like or equal to discharge a weight at the ship's keel, causing a bodily rise and change of trim. It is better for calculation accuracy to use two different methods and compare the results, if the results are not close, must recalculate.

\subsection{Residual Buoyancy Method}

This method is the preferable and the most accurate to determining the total ground reaction, especially when the ship hull deflected from grounding, this method gives credible estimated of LCB, which is necessary to locate the longitudinal center of ground reaction LCR. It is more suitable for use with computers to calculate the exact hull form.

The area between the weight curve and the grounded ship residual buoyancy curve is the total ground reaction, although the shape of this area does not refer to the ground reaction. The load curve formed by the sum of weight curve and buoyancy plus ground reaction curves, the load curve is not zero at every point, even though overall equilibrium exists. The ground reaction must be distributed so that the combined force of buoyancy (B) pulse the ground reaction (R) is in the vertical line with the force of ships weight $(\mathrm{G})$. By applying the principles discussed in 3. Determination of total ground reaction (R) location, the ground reaction distribution may be described with reasonable accuracy.

\subsection{Change of Displacement Method}

This method is almost suitable for all grounding situations. In this method calculating the difference in displacement is before and after grounding from hydrostatic curve or table by using the draft.

$$
\mathrm{R}=\Delta_{O}-\Delta_{g}
$$

$\mathrm{R}=$ Total ground reaction $(\mathrm{R})$ tons.

$\Delta_{O}=$ Original displacement before grounding, tons.

$\Delta_{g}=$ Displacement after grounding, tons.

Correction to displacement should be done in case of trimmed ship and center of floatation $\left(\mathrm{F}_{\mathrm{c}}\right)$ is not at the amidships section.

where,

If the center of floatation $\left(\mathrm{F}_{\mathrm{c}}\right)$ is aft of amidships.

a - ship trimmed by aft, decrease in amidships draft and decrease the displacement;

b- ship trimmed by forward, increase in amidships draft and increase the displacement.

If the center of floatation $\left(F_{c}\right)$ is forward of amidships.

a - ship trimmed by aft, increase in amidships draft and increase the displacement;

b-ship trimmed by forward, decrease in amidships draft and decrease the displacement.

Corrections applied to amidships mean draft to give accurate displacement from hydrostatic table or curve, by using that equation:

$$
T_{c}=\frac{d_{f} \cdot t}{L}
$$

where,

$T_{c}=$ Trim correction;

$d_{f}=$ Distance between center of floatation $\left(\mathrm{F}_{\mathrm{c}}\right)$ and amidships (LCF), m; 
$\mathrm{t}=$ Trim, $\mathrm{m}$;

$\mathrm{L}=\mathrm{LBP}$ (length between perpendiculars), $\mathrm{m}$.

Equivalent mean

$$
\begin{aligned}
& =\text { Mean Draft } \\
& \pm \text { Trim Correction. }
\end{aligned}
$$

( + if trim aft and LCF aft of amidships or trim forward and LCF forward).

(- if trim aft and LCF forward of amidships or trim forward and LCF aft).

If ship trims less that $1 \%$ of length between perpendiculars (LBP), corrected displacement can be calculated by multiplying TC (trim correction) by tons per $1 \mathrm{~cm}$ immersion (TPC) and add/subtract from original displacement.

\subsection{Tons per $1 \mathrm{~cm}$ Immersion Method}

This method is suitable for the first estimate of total ground reaction $(\mathrm{R})$ and prefer to calculating ground reaction $(\mathrm{R})$ by multiplying the change in the corrected mean draft before grounding and after grounding by the tons per $1 \mathrm{~cm}$ immersion (TPC).

$$
R=\left(d r_{O}-d r_{g}\right) \cdot T P C
$$

where,

$d r_{O}=$ Original corrected mean draft (corrected to trim);

$d r_{g}=$ Corrected mean draft after grounding, corrected to trim.

\subsection{Change of Trim Method (Ch. O. T)}

This method is suitable when the ship trim exceeds $1 \%$ of ship's length between perpendicular (LBP) and center of pressure of the ground reaction is known or can be estimated, to know trimming lever, this method may prove effective when the ship is ground at a single point, where is easy to locate the center of ground pressure.

The change of trim (Ch. O. T) is the effect of grounding.

$$
\text { Ch. O.T }=\frac{R \cdot l_{R}}{M C T C}
$$

$$
R=\frac{M C T C \cdot C h \cdot O \cdot T}{l_{R}}
$$

where,

MCTC $=$ Moment to change trim $1 \mathrm{~cm}$, before grounding;

$l_{R}=$ Distance between center of ground reaction $(\mathrm{R})$ and center of floatation (LCF).

\subsection{Change of Draft Method}

This method is suitable when the center of pressure of the ground reaction is known or can be estimated, to know the trimming lever. In this method consider the ground reaction as equivalent to a weight removal that causes both parallel rise and change of trim (Fig. 6).

$$
\text { Ch.O. } d r_{f}=d r_{f b}-d r_{f a}=\text { Ch.O.T } \cdot \frac{l_{f}}{L}+\frac{R}{T P C}
$$

where,

Ch. O. $\mathrm{dr}_{\mathrm{f}}=$ Change of draft forward before and after grounding;

$d r_{f b}=$ Draft forward before grounding;

$d r_{f a}=$ Draft forward after grounding;

Ch.O.T = Change of trim before and after grounding;

$l_{f}=$ Distance between center of ground reaction (R) and center of floatation $\left(\mathrm{F}_{\mathrm{c}}\right)$.

$$
\begin{array}{r}
\text { Ch.O. } d r_{f}=\frac{R \cdot l_{R}}{M C T C} \cdot \frac{l_{f}}{L}+\frac{R}{T P C} \\
R=\frac{\left(d r_{f b}-d r_{f a)} \cdot T P C \cdot M C T C . L\right.}{M C T C \cdot L+l_{f} \cdot l_{R} \cdot T P C}
\end{array}
$$

\section{Location of Neutral Loading Point}

Neutral loading point is a point where weight can be added or removed without any change in the total ground reaction (R). At this point, the increase of draft caused by parallel sinkage on the grounding point $(\mathrm{P})$ is exactly the same of the change of draft (Fig. 7).

Parallel Sinkage $=$ Change of Draft

$$
\frac{w}{T P C}=\frac{w \cdot d_{n}}{M C T C} \cdot \frac{d_{r}}{L}
$$

$$
d_{n}=\frac{M C T C \cdot L}{T P C \cdot d_{r}}
$$




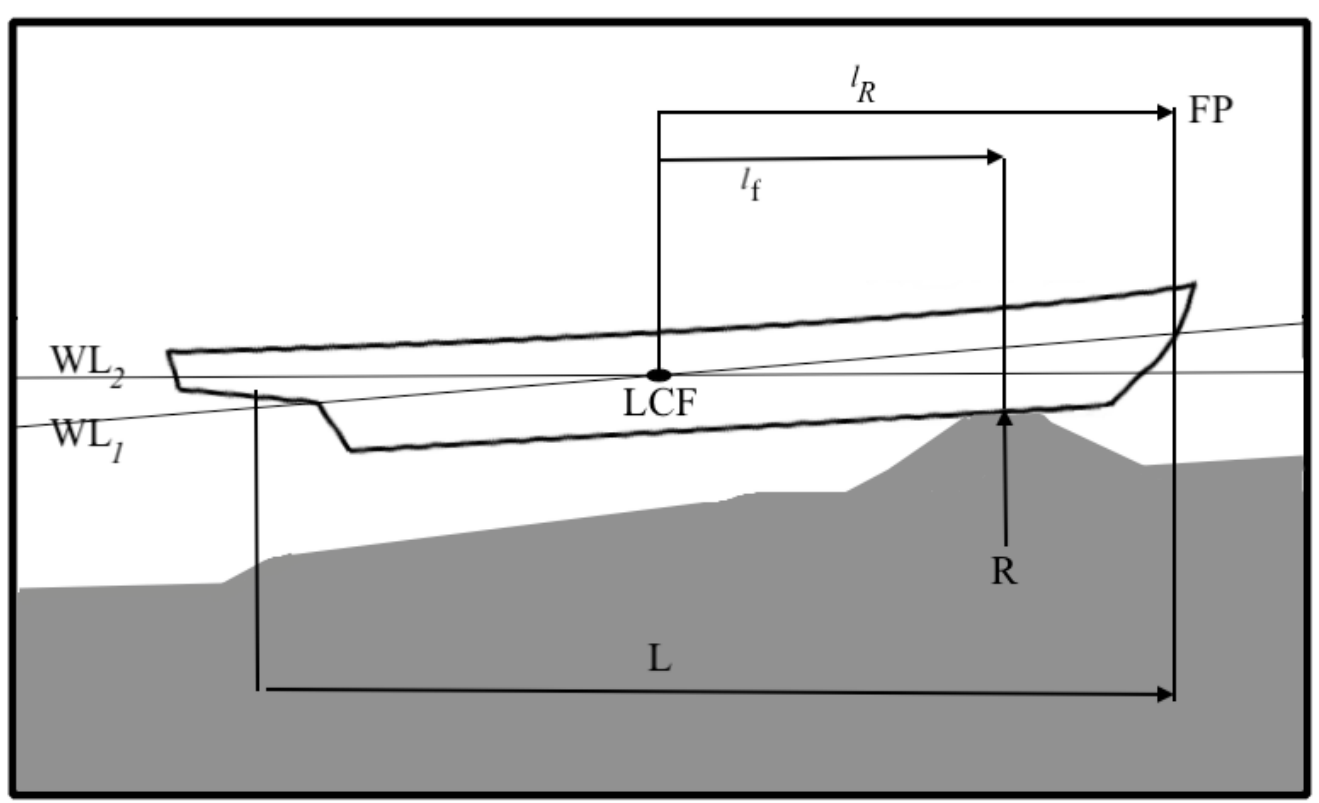

Fig. 6 Change of draft effect.

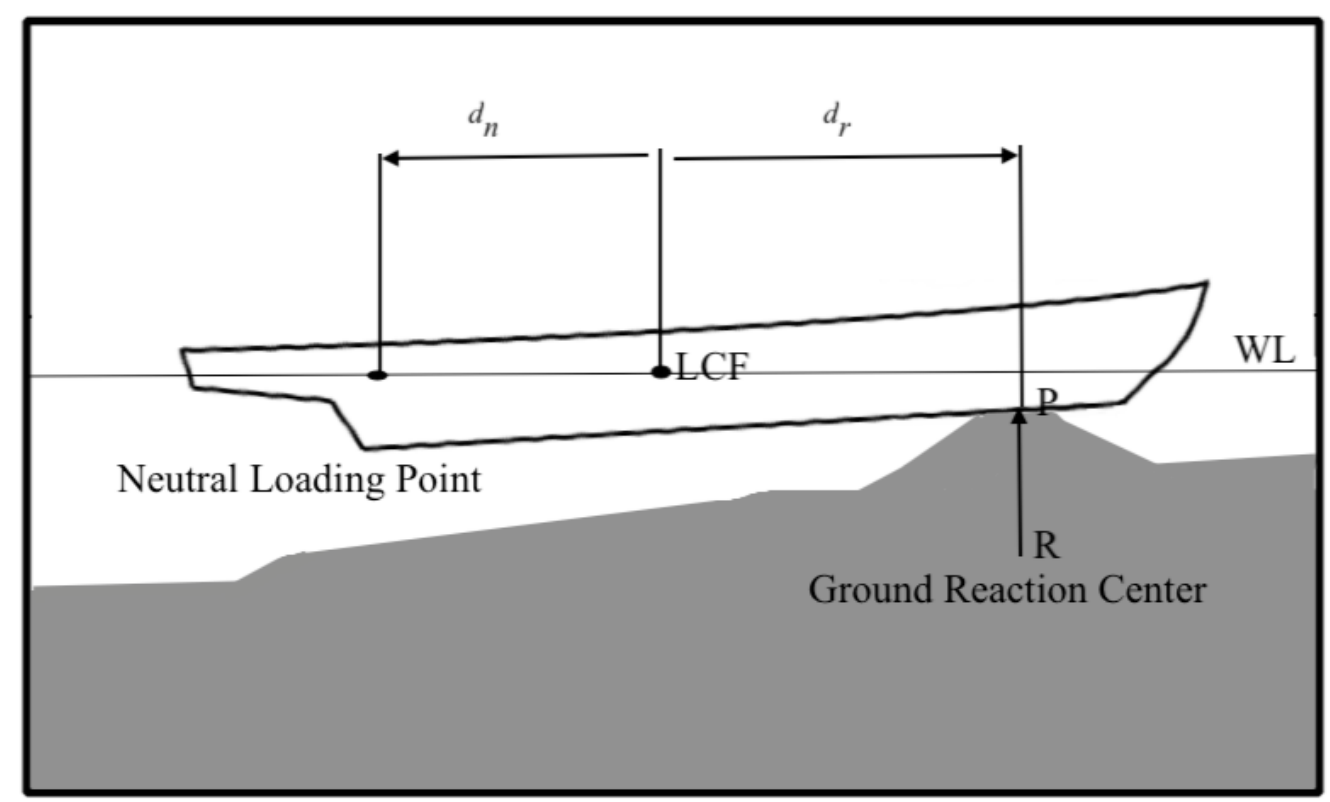

Fig. 7 Determine the location of neutral loading point.

where,

$\mathrm{w}=$ Is the added weight, tons;

$d_{n}=$ Distance from added weight to center of floatation $\left(\mathrm{F}_{\mathrm{c}}\right)$, based on grounding draft;

$d_{r}=$ Distance from center of pressure $(\mathrm{P})$ to center of floatation $\left(\mathrm{F}_{\mathrm{c}}\right)$.

the neutral loading point work as an indicator to help to predict the effect of weight change at other locations.
Since loading weight aft of that point will decrease the ground reaction, weight add forward this point will increase ground reaction. The opposite is true for weight removed.

The position of the neutral point must be recalculated if significant changing is to the weight, and the ship will trim, which is because the ship characteristics (MCTC, TPC, LCF) will change. 
This method is not applicable if the grounded length increased, the distance between the center of floatation $\left(F_{c}\right)$ and the center of ground reaction is less than $1 / 8 L B P$; whereas the neutral loading point will be located outside the ship.

\section{Effect of Changing Weight on the Ground Reaction for Single Point Grounding}

When the ship grounding at single point draft cannot be increased at this point, the ship is not anymore trimmed about the center of floatation $\left(\mathrm{F}_{\mathrm{c}}\right)$, but it trimmed about the center of reaction $(\mathrm{P})$. Since, the weight changing is the preferred method and first choice for reducing ground reaction, at the stage of re-floating, there are weights that must either add, remove or shift. In case of adding or removing weights, the displacement will change, any change to the displacement must reflect on the sum of the buoyance and the ground reaction.

If the grounded ship did not respond to the weight change by trim or change of trim, which means the volume of displacement hence the buoyancy is unchanged, which means that the increment in ground reaction.

$$
\Delta R= \pm w
$$

where,

$\Delta R=$ The change in ground reaction;

$\mathrm{W}=$ The weight added/removed.

Using neutral loading point can predict the weight effect to the ground reaction. The weight added or removed at the center of ground reaction (P) will change the ground reaction equal to the weight change without a change in buoyancy and trim. The weight added or removed at the neutral loading point will change in buoyancy and trim without a change in ground reaction $(\mathrm{R})$.

Changing weight ratio and the ground reaction (R) can assume as a linear relationship between the neutral loading point as $0 \%$ and the center of ground reaction (R) as $100 \%$ can thus be predicted by the following relationship (Fig. 8):

$$
\Delta \mathrm{R}=w \cdot\left(\frac{d}{d_{n r}}\right)
$$

where,

$\mathrm{d}=$ Distance from the added/removed weight to the neutral loading point;

$d_{n r}=$ Distance from the neutral loading point to the center of ground reaction $(\mathrm{P})$;

$$
=d_{r}+d_{n}
$$

$d_{n}=$ Distance from added weight to center of floatation $\left(\mathrm{F}_{\mathrm{c}}\right)$, based on grounding draft;

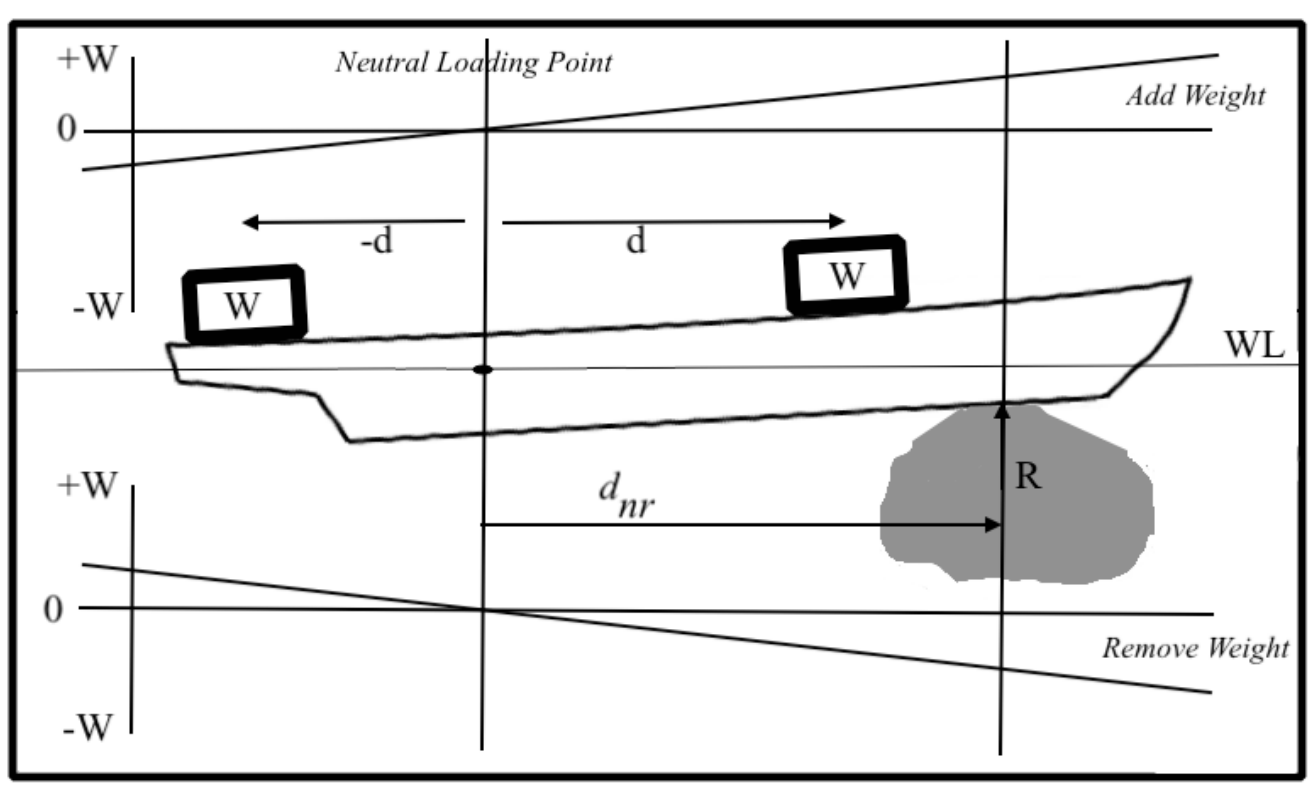

Fig. 8 Influence of add/remove weight on the ground reaction through the neutral loading point. 


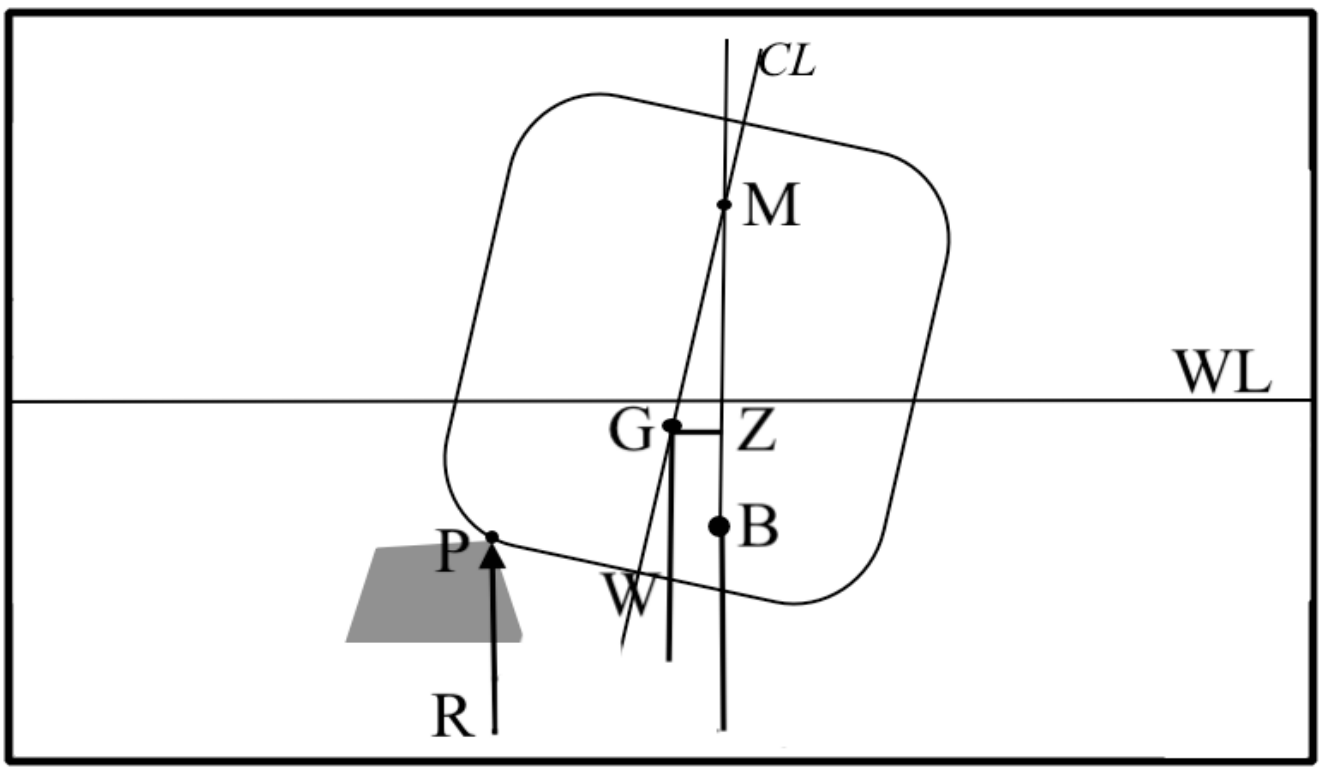

Fig. 9 Influence of side ship grounding.

$d_{r}=$ Distance center of floatation $\left(\mathrm{F}_{\mathrm{c}}\right)$ to center of pressure $(\mathrm{P})$.

Although this relationship and the plot in (Fig. 9) imply that removing weights from forward of the center of ground reaction will reduce ground reaction by an amount greater than the weight removed, this is true only for a ship grounded on a summit with a significant portion of the ship forward of the summit.

\section{Effect of Changing Weight on the Draft Forward and Aft}

The change in buoyancy leads to change in trim thus change in forward and aft draft, which can be calculated by:

$$
\begin{gathered}
\Delta d r_{m}=\frac{\Delta B}{T P C} \\
\Delta d r_{a}=\frac{\Delta B}{T P C} \cdot \frac{l_{2}+d_{r}}{d_{r}} \Delta d r_{f}=\frac{\Delta B}{T P C} \cdot \frac{-d_{f}}{d_{r}} \\
\text { Or } \Delta d r_{f}=\Delta d r_{m}-\Delta d r_{f}
\end{gathered}
$$

where:

$\Delta d r_{m}=$ Change in mean draft due to add/remove weight;

$\Delta B=$ Change in buoyancy;

$\Delta d r_{a}=$ Change in draft aft;

$l_{2}=$ Distance from center of floatation (LCF) to aft perpendicular; $d_{r}=$ Distance center of floatation $\left(\mathrm{F}_{\mathrm{c}}\right)$ to center of pressure (P);

$\Delta d r_{f}=$ Change in draft forward;

$d_{f}=$ Distance from center of pressure $(\mathrm{P})$ to forward perpendicular.

In the normal grounding situation, where the center of ground pressure (P) is forward of the center of floatation $\left(\mathrm{F}_{\mathrm{c}}\right)$ and aft of the forward perpendicular, increase in the mean draft and aft draft will be noticed, but decrease in forward draft.

When the center of the ground reaction pressure $(\mathrm{P})$ is way forward, the aft draft will nearly increase twice of the middle draft with ignore to forward draft.

\section{Transverse Stability for Grounding Ship}

The effect of the grounding of ship stability is determined by the way the ship remains on the seabed, if the ship grounds on a flat seabed, there is a small chance of capsizing. But if the ship grounded on the summit it would be free for more inclining.

The reaction of the ground $(\mathrm{R})$ will produce a heeling moment, causing a loss in the ship stability. The situation may go even worse and the ground reaction may develop later, especially in case of tide ebbs (Fig. 9).

Transverse stability calculation must be done, due to 
the difference in ship stability characteristics.

\subsection{Virtual Rise in the Ship Center of Gravity $(G)$}

The ground reaction $(\mathrm{R})$ has the same effect on ship stability as does the removal of the weight at the keel, and that causing a virtual rise in the center of gravity $(G)$ which can be calculated by:

$$
G G_{1}=\frac{R \cdot K G}{W-R} K G_{1}=\frac{W \cdot K G}{W-R}
$$

where:

$$
\begin{aligned}
& G G_{1}, K G_{1}=\text { Calculated, after grounding; } \\
& \mathrm{KG}=\text { Original } \mathrm{KG} ; \\
& \mathrm{W}=\text { Ship displacement. }
\end{aligned}
$$

\subsection{Change in Meta-centric Height after Grounding} (GM)

Ship characteristics after grounding are based on the residual buoyancy of the ship, since that grounding is a loss in buoyancy. The underwater volume was changed thus the water plan area changed. The moment of inertia about the center line is changed too, since:

$$
\begin{gathered}
K M=K B+B M \\
K B=d r-\frac{1}{3}\left(\frac{V}{A}+\frac{d r}{2}\right)
\end{gathered}
$$

$$
\begin{aligned}
& B M=\frac{I}{V} \\
& I=\frac{L B^{3}}{12}
\end{aligned}
$$

where:

$\mathrm{dr}=$ Ship draft after grounding;

$\mathrm{V}=$ Residual underwater volume;

$\mathrm{A}=$ Residual water plane area;

$\mathrm{I}=$ The second moment of inertia about the center line;

$\mathrm{L}=$ Ship's water plane area length;

$\mathrm{B}=$ Ship's water plane area breadth.

\subsection{Upsetting Moment vs. Righting Moment}

The upsetting moment caused by the ground reaction in case of side ship grounding, can be calculated by assuming that the ship will incline by reaction force until the moment of residual buoyancy about contact point $(\mathrm{P})$ becomes equal to the moment of ship's weight about the same point $(\mathrm{P})$; when (Fig. 10):

$$
R \cdot d_{r}=B \cdot d_{b}=W_{f} \cdot G Z=W \cdot G M_{f} \cdot \operatorname{Sin} \theta
$$

where:

$\mathrm{R}=$ Ship's ground reaction;

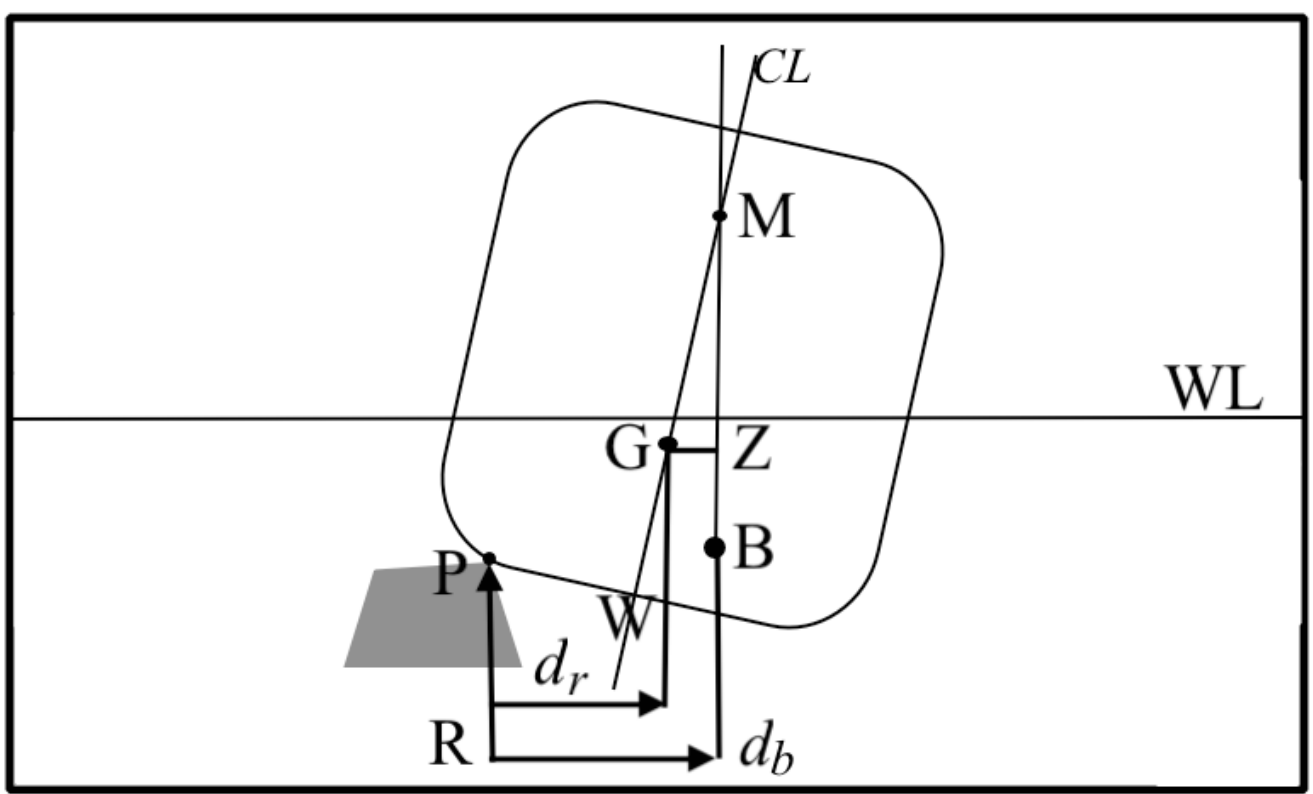

Fig. 10 Upsetting moment vs. righting moment. 
$d_{r}=$ Distance from ground reaction point $(\mathrm{P})$ to the center line;

$\mathrm{B}=$ Force of residual buoyancy;

$d_{b}=$ Distance from ground reaction point $(\mathrm{P})$ to the center of buoyancy;

$\mathrm{W}=$ Ship gross displacement;

$G M_{f}=$ Corrected GM after grounding.

\section{Conclusions}

Grounded ship is vulnerable to loss of buoyancy, where variance between buoyancy and weight causes pressure from the seabed on ship's hull, this pressure can be called ground reaction $(\mathrm{R})$. There are many influences on buoyancy, ship's condition, ship's stability characteristics and GM due to the ground reaction. Re-floating decision requires good comprehension for ground reaction $(\mathrm{R})$ and accurate calculation of ship stability condition after grounding.

In this paper it is presented a guide to understanding the ground reaction $(\mathrm{R})$ and how to calculate the amount of that reaction by using simple equation by ship's crew. To determine ground reaction (R) location must consider the distribution of the ground reaction ( $\mathrm{R}$ ) amount on the ship's hull depend on ground length and seabed form, either be symmetric seabed or asymmetric seabed. There are five different applicable methods that can be done by the crew to calculate the magnitude of the ground reaction $(\mathrm{R})$, residual buoyancy method, change of displacement method, tons per $1 \mathrm{~cm}$ immersion method, change of trim method and change of draft method. Taking into account that all methods are approximate except residual buoyancy method, crew must calculate ground reaction by two different methods, the most accurate results should be expected from change of trim method when the trim is greater than $1 \%$ of the ship's length; trim correction must be done in all methods. Adding or removing weight can be done to re-float the ship, the crew can calculate the location which can add weight on that location without changing in ground reaction magnitude by using simple equation.

\section{References}

[1] "Annual Overview of Marine Casualties and Incidents." European Maritime Safety Agency, Lisboa Portugal. 2016.

[2] The Association of Hanseatic Marine Underwriters (VHT-Verein Hanseatischer Transportversicherer e.V.) Ground Reaction. 2012.

[3] Hussein, A. W., El-Dessouky, U. M., El-Kilani, H. S., and Hegazy, E. H. 2016. "Grounding Contingency Plan for Intact Double Hull Tanker." Alexandria Engineering Journal 55 (1): 235-41.

[4] Varsami, A., and Chircor, M. 2011. "Stranded Ships and Their Salvage." Constanta Maritime University Annals. 12 (15): 105-9.

[5] Varsami, A. E., Chircor, M., Popescu, C., and Hanzu-Pazara, R. 2012. "Refloating a Ship Using Her Own Means." Annal \& Proceedings of DAAAM International.

[6] de Sousa Bastos, P. C., and Tapia Reyes, M. C. 2014. "Stability of Ships with a Single Stranding Point." Ship Science and Technology 7 (14).

[7] Varsami, A., Belev, B., and Hanzu-Pazara, R. 2013. "The Concept and Calculus of 'Refloating a Ship' Applied to Grounded Ships."

[8] "Stranding, Harbor Clearance and Afloat Salvage." Direction of Commander, Naval Sea Systems Command, U.S. Navy Salvage Manual-Volume 1, 2013.

[9] Direction of Commander, Naval Sea Systems Command, U.S. Navy Salvage Engineer's Handbook-Volume 1.

[10] Direction of Commander, Naval Sea Systems Command, U.S. Navy Salvor's Hand Book. 2004. 